\title{
Association of Different Interventions to Increase Leukocyte Testing During Treatment With Dimethyl Fumarate
}

Paul Heidenreich ( $\square$ heiden@stanford.edu )

VA Palo Alto Health Care System https://orcid.org/0000-0001-7730-8490

Anju Sahay

VA Palo Alto Health Care System

Shoutzu Lin

VA Palo Alto Health Care System

Parisa Gholami

VA Palo Alto Health Care System

Mary Goldstein

VA Palo Alto Health Care System

Von Moore

VA Center for Medication Safety

Muriel Burk

VA Center for Medication Safety

Peter Glassman

VA Greater Los Angeles Healthcare System

Francesca Cunningham

VA Center for Medication Safety

Short report

Keywords: Safety, Pharmacy education, Leukopenia

Posted Date: January 20th, 2021

DOI: https://doi.org/10.21203/rs.3.rs-149132/v1

License: (c) (i) This work is licensed under a Creative Commons Attribution 4.0 International License.

Read Full License 


\section{Impact.Association of Different Interventions to Increase Leukocyte Testing During Treatment with Dimethyl Fumarate}

Paul A. Heidenreich MD, MS ${ }^{1,2}$

Anju Sahay PhD ${ }^{1}$

Shoutzu Lin MS ${ }^{1}$

Parisa Gholami MPH ${ }^{1}$

Mary Goldstein MD, MS 1,2

Von R. Moore, PharmD ${ }^{3}$

Muriel L. Burk, PharmD ${ }^{3}$

Peter A. Glassman, MBBS, MSc $^{4}$

Francesca E. Cunningham, PharmD ${ }^{3}$

${ }^{1}$ Veterans Administration Palo Alto Healthcare System, Palo Alto, CA, ${ }^{2}$ Department of Medicine, Stanford University School of Medicine, Stanford, CA, ${ }^{3}$ VA Center for Medication Safety, Hines, IL. ${ }^{4}$ VA Greater Los Angeles Healthcare System, Los Angeles, CA

Word Count: Abstract 260

Text Word Count (including references): 2322

Corresponding Author: Paul Heidenreich, MD

Email: heiden@stanford.edu 


\section{ABSTRACT}

Background: Dimethyl fumarate (DMF), a treatment for multiple sclerosis, may cause leukopenia and infection. Accordingly, periodic white blood cell (WBC) monitoring is recommended. We sought to evaluate the VA Medication Use Evaluation Tracker (MUET) initiative which provides VA facilities with a list of patients prescribed DMF therapy without a documented white blood cell count (WBC).

Methods: We identified 118 VA facilities with patients treated with DMF from 1/1/2016 through 9/30/2016. We determined WBC measurements within three months of the first filled prescription. The lead pharmacist at each facility was surveyed asking if any of seven intervention types were used to improve WBC monitoring (academic detailing, provider education without academic detailing, electronic clinical reminders, request for provider action plan, draft orders for WBC monitoring, patient mailings, and patient calls).

Results: The facility response rate for the survey was $78 \%$ (92 of 118 facilities). For the 92 included facilities $(1,115$ patients) the mean rate of WBC monitoring was $54 \%$. Use of the at-risk patient lists was noted in 55\% (51/92) of facilities. In multivariate analysis, only academic detailing and provider education remained significantly associated with higher WBC monitoring. From a base WBC monitoring rate of $46 \%$, academic detailing increased the rate by $17 \%$ (95\% $\mathrm{Cl} 4$ to $30 \%, \mathrm{p}=0.011)$ and provider education increased the rate by $9 \%(95 \% \mathrm{Cl} 0.6$ to $18 \%$, $p=0.037)$. The WBC monitoring rate increased by $3.8 \%$ for each additional intervention used (95\% Cl 1.2\%-6.4\%, $\mathrm{p}=0.005)$.

Conclusions: Interventions focused on the physician, including academic detailing, were associated with improved WBC monitoring for patients at risk for leukopenia from dimethyl fumarate treatment. 


\section{Key Words}

Safety, Pharmacy education, Leukopenia

\section{Contributions to the literature}

- Research has shown that just making quality metrics available to facilities may not lead to improved care.

- Our study emphasizes the importance of pharmacist interactions with providers in improving care.

- These findings help to fill gaps in knowledge regarding how facilities can act when receiving data on potential gaps in care.

\section{INTRODUCTION}

Dimethyl fumarate (DMF), a medication for treatment of multiple sclerosis and advanced psoriasis, can cause leukopenia which has been associated with infection including fatal progressive multifocal leukoencephalopathy. [1, 2] Accordingly, white blood cell monitoring is recommended for those on DMF therapy so treatment can be adjusted or discontinued if leukopenia occurs.

To improve the safety of DMF use, the VA has included this medication as part of its National Medication Use Tracker (MUET) safety program. [3] The DMF MUET program identifies potentially at-risk patients filling prescriptions for DMF therapy either without a documented VA white blood cell count (WBC) follow-up within 3 months of a released prescription, or with a dangerously low WBC. [Appendix] MUET provides pharmacists at VA medical centers with secured lists of patients who meet these at risk criteria, and the VA pharmacists then intervene at their discretion. Thus, different interventions are used by different VA facilities. The purpose of this study was to evaluate participation in the DMF MUET initiative, determine use of different interventions to improve WBC monitoring, and determine if any intervention was associated with greater WBC monitoring. 


\section{METHODS}

\section{VA Facilities}

We identified VA facilities with patients who filled prescriptions for DMF during the target time period (1/1/2016-9/30/2016). This time period was selected to obtain a study size that should be adequate to detect a 10\% difference in WBC monitoring between strategies. Facilities are made up of at least one hospital with one or more outpatient clinics which may be dispersed geographically. Hospital characteristics were determined using linkage with survey data from the American Hospital Association to determine membership in the Council of Teaching Hospitals and presence of accredited graduate medical education programs.

\section{Pharmacy-Led Interventions}

VA Pharmacy leadership identified seven interventions known to be used by local pharmacists: 1) academic detailing by pharmacists, 2) provider education without academic detailing, 3) electronic clinical reminders, 4) draft orders for WBC testing, 5) request for care plan from the provider, 6) patient calls, and 7) patient mailings. Pharmacists were surveyed to determine if any of these seven interventions were used at their facility. If more than one pharmacist responded from a given facility, we used the response from the pharmacist in the highest leadership position.

\section{White Blood Cell Count Monitoring}


The primary outcome was white blood cell count monitoring in the 90 days after a filled prescription for DMF at the facility level expressed as a percent of all patients with a filled DMF prescription.

\section{Statistical Analyses}

We compared means of facility rates of 90-day WBC monitoring for facilities grouped by the use of the seven interventions described above (facility level analysis). We weighted all analyses using the number of patients with a filled prescription at each facility. To determine the interventions independently associated with higher WBC monitoring we performed a forward stepwise regression analysis where interventions were entered sequentially (in order of statistical significance from unadjusted analyses) and then removed if the $p$ value remained $>$ 0.10. A P-value $<0.05$ was considered statistically significant for this exploratory analysis.

The survey and primary analysis were performed as part of VA operations (quality improvement) to determine the efficacy of the MUET program. Facilities that did not respond to the survey (missing data) were not included in the analysis. IRB approval (Stanford University) was obtained to perform additional (secondary) analyses for publication. The manuscript adheres to the STROBE recommendations for cohort studies (supplementary material). 


\section{RESULTS}

We identified 118 VA Health Care systems (facilities) treating patients with DMF. The facility response rate for the survey of interventions was $78 \%$ (92 of 118 facilities). The 92 facilities $(1,115$ patients) were located more in the South $(41 \%)$ and Midwest $(24 \%)$, compared with the Northeast (20\%) and West (15\%). Data regarding academic status from the American Hospital Association were available for 89 of 92 facilities (97\%), of which 34 (38\%) were members of the Council of Teaching Hospitals (COTH) and 68 (76\%) had accredited graduate medical education (ACGME) programs. There were no significant differences in characteristics between responding and non-responding facilities.

\section{Use of the Dimethyl Fumarate Safety Monitoring Initiative}

Among the 92 responding facilities, 51 (55\%) reported participating in the DMF safety initiative of the Medication Use Evaluation Tracker (MUET). Of these, the initiative was described as very useful by $20(39 \%)$, useful by $27(53 \%)$ and not useful by $4(8 \%)$.

\section{Interventions and WBC Monitoring}

Among those facilities participating in the DMF MUET safety initiative, the mean rate of WBC monitoring was $54 \%$. Monitoring was greater in those facilities describing the DMF safety initiative participation as useful $(55 \% \pm 15 \%)$ compared to those saying that participation was not useful $(37 \% \pm 18 \%, p=0.03)$. Table 1 describes the use of the seven interventions and the rates of WBC monitoring for facilities using those interventions. The interventions with the greatest impact on WBC monitoring were academic detailing, draft orders for WBC testing, provider education and a request for provider management plan. 


\section{Adjusted Analyses}

In stepwise multivariate analysis, only academic detailing and provider education remained significantly associated with WBC monitoring. In this model, doing neither of these interventions was associated with a WBC monitoring rate of $46 \%$. Academic detailing increased the rate by $17 \%(95 \%$ confidence interval 4 to $30 \%, p=0.011)$ and provider education increased the rate by $9 \%(95 \%$ Cl 0.6 to $18 \%, p=0.037)$.

\section{Number of Interventions}

Overall, $82 \%$ of participating facilities (42/51) reported using at least one intervention, $55 \%$ $(28 / 51)$ used two or more and $33 \%(17 / 51)$ used three or more interventions. Monitoring of WBC increased with increasing number of interventions used (Figure). When WBC monitoring rate was examined as a continuous variable, the WBC monitoring rate increased by $3.8 \%$ for each additional intervention (95\% $\mathrm{Cl} 1.2 \%-6.4 \%, \mathrm{p}=0.005)$.

\section{Barriers to Participation}

The reasons for lack of any participation or discontinuation are shown in Table 2 for the 41 facilities that did not participate. Most $(75 \%, 31 / 41)$ provided at least one reason for lack of participation. The most common reasons were lacking enough patients taking DMF to make this worthwhile, a concern that participating will be too time consuming, and the lack of real time data. Among facilities those that discontinued their involvement with the DMF initiative, $36 \%$ felt their providers were educated adequately. 


\section{DISCUSSION}

Our study examined facility participation in the VA's Medication Use Evaluation Tracker (MUET)

program [3] that identifies patients taking dimethyl fumarate (DMF) who were not monitored with a white blood cell (WBC) count. We found that VA facilities participating in the DMF MUET program use a variety of interventions to improve WBC monitoring for patients taking DMF. Facilities were free to select which interventions to implement to improve safety monitoring of patients taking DMF. The most common interventions used were electronic reminders, provider education and a request for a provider management plan. We took advantage of this natural experiment to evaluate the association of these interventions with higher WBC monitoring.

We identified two of seven pharmacy-led interventions that were significantly and independently associated with higher WBC monitoring of patients taking Dimethyl Fumarate (DMF). After adjustment, WBC monitoring increased above the baseline of $46 \%$ by $9 \%$ if provider education (without academic detailing) was used and by $17 \%$ if academic detailing was used. While other interventions did not reach statistical significance at the $p<0.05$ level, there were trends toward improved monitoring with most interventions. The more interventions used the higher the (WBC) monitoring with a $4 \%$ increase in monitoring for each additional intervention used.

Academic detailing has been successful in multiple care settings, [4-6] though the specific methods of successful detailing are unclear. [7] Within the VA, academic detailing of VA pharmacists to primary care providers has been demonstrated to reduce potentially inappropriate medications in a pre-post analysis. [8]

Medication alert messages at the point of computerized provider order entry (CPOE) have been evaluated for reducing potentially inappropriate medications [9] in elderly Veterans. [10] In a pre-post design, electronic alerting was not associated with a reduction in potentially inappropriate medication use, though a significant reduction was found when limited to the top 
10 most common newly prescribed potentially inappropriate medications, $9.0 \%$ to $8.3 \%$ $(P=0.016)$ [10]. In randomized trials, electronic medication alerts have been successful in modifying prescribing patterns, but the effect is modest often requiring a large sample size to demonstrate significance. [11,112 This is consistent with our study's finding that electronic reminders appeared promising but not as strong as academic detailing.

One reason for not participating in the initiative was the lack of real time data. Thus, use of a dashboard to disseminate patient information may increase participation. While not specifically asked in the survey, several of the facilities not participating were known to have access to a local dashboard.

There are several potential limitations of the evaluation. Facilities were not randomized to the different interventions and it is possible that differences in facilities (e.g. attitudes towards safety) may have led to both the use of interventions and improved WBC monitoring. It is possible that some patients may have had lab testing at non-VA facilities. Such unobserved testing would have biased the results towards the null, making it more difficult to see significant associations. Variation in delivery of the strategies is likely to have occurred across facilities (e.g. different ways and persistence in delivering provider education or academic detailing). Large variation in delivery would make it more difficult to see significant effects so our positive findings for certain strategies suggests they mav be robust to variation in adaption. Finally, VA facilities may be more amenable to implementation of quality improvement interventions than non-VA hospitals.

\section{Conclusions}


In summary, we found that provider education, particularly through pharmacist led academic detailing, was associated with improved WBC monitoring for patients treated with dimethyl fumarate. Wider implementation of provider education to improve lab monitoring for medication safety should be studied.

\section{LIST OF ABBREVIATIONS}

ACGME: accredited graduate medical education

COTH: Council on Teaching Hospitals

DMF: dimethyl fumarate

MUET: Medication Use Evaluation Tracker

VA: Veterans Affairs

WBC: white blood cell

\section{DECLARATIONS}

Ethics approval and consent to participate: The study was conducted as part of operations for the VA health care system though additional analyses were performed as research approved by the Stanford University Institutional Review Board.

Consent for publication: Not Applicable

Availability of data and materials: The datasets used and/or analyzed during the current study are available from the corresponding author on reasonable request.

Competing interests: The authors declare that they have no competing interests.

Funding: The study was funded in part by a grant from the VA Quality Enhancement Research Initiative. The funder had no direct role in the design of the study or collection, analysis, and interpretation of data. The funder had no role in writing the manuscript.

Authors' contributions: $\mathrm{PH}, \mathrm{AS}, \mathrm{FC}, \mathrm{MG}, \mathrm{VM}, \mathrm{PG}$ and MB made substantial contributions to the conception and design of the work; PG, SL, PH and AS, MG and VM provided data acquisition, 
$\mathrm{PH}, \mathrm{SL}$, and AS conducted data analysis, All authors provided interpretation of data; $\mathrm{PH}$ drafted the document and all authors provided important review and revision.

Acknowledgements: Not Applicable

Authors' information: No additional Information 


\section{REFERENCES}

1. Saidu NEB, Kavian N, Leroy K, Jacob C, Nicco C, Batteux F, Alexandre J. Dimethyl fumarate, a two-edged drug: Current status and future directions. Med Res Rev. 2019 [In Press]

2. Mrowietz U, Barker J, Boehncke WH, Iversen L, Kirby B, Naldi L, Reich K, Tanew A, van de Kerkhof PCM, Warren RB. Clinical use of dimethyl fumarate in moderate-tosevere plaque-type psoriasis: a European expert consensus. J Eur Acad Dermatol Venereol. 2018;32 Suppl 3:3-14.

3. Burk M, Moore V, Glassman P, Good CB, Emmendorfer T, Leadholm TC, Cunningham F. Medication-use evaluation with a Web application. Am J Health Syst Pharm. 2013 Dec 15;70(24):2226-34.

4. Alagoz E, Chih MY, Hitchcock M, Brown R, Quanbeck A. The use of external change agents to promote quality improvement and organizational change in healthcare organizations: a systematic review. BMC Health Serv Res. 2018 Jan 25;18(1):42.

5. Fischer MA. Academic Detailing in Diabetes: Using Outreach Education to Improve the Quality of Care. Curr Diab Rep. 2016 Oct;16(10):98.

6. O'Brien MA, Rogers S, Jamtvedt G, Oxman AD, Odgaard-Jensen J, Kristoffersen DT, Forsetlund L, Bainbridge D, Freemantle N, Davis DA, Haynes RB, Harvey EL. Educational outreach visits: effects on professional practice and health care outcomes. Cochrane Database Syst Rev. 2007 Oct 17;(4):CD000409.I

7. Van Hoof TJ, Harrison LG, Miller NE, Pappas MS, Fischer MA. Characteristics of Academic Detailing: Results of a Literature Review. Am Health Drug Benefits. 2015 Nov;8(8):414-22. 
8. Vandenberg AE, Echt KV, Kemp L, McGwin G, Perkins MM, Mirk AK. Academic Detailing with Provider Audit and Feedback Improve Prescribing Quality for Older Veterans. J Am Geriatr Soc. 2018 Mar;66(3):621-627.

9. American Geriatrics Society 2012 Beers Criteria Update Expert Panel. American Geriatrics Society updated Beers Criteria for potentially inappropriate medication use in older adults. J Am Geriatr Soc. 2012;60(4):616-631.

10. Vanderman AJ, Moss JM, Bryan WE 3rd, Sloane R, Jackson GL, Hastings SN. Evaluating the Impact of Medication Safety Alerts on Prescribing of Potentially Inappropriate Medications for Older Veterans in an Ambulatory Care Setting. J Pharm Pract. 2017 Feb;30(1):82-88.

11. Heidenreich PA, Gholami P, Sahay A, Massie B, Goldstein MK. Clinical reminders attached to echocardiography reports of patients with reduced left ventricular ejection fraction increase use of beta-blockers: a randomized trial. Circulation. 2007;115(22):2829-34.

12. Heidenreich PA, Chacko M, Goldstein MK, Atwood JE. ACE inhibitor reminders attached to echocardiography reports of patients with reduced left ventricular ejection fraction. Am J Med. 2005;118(9):1034-7. 


\section{Figure Legends}

Figure 1: The rate of WBC monitoring is shown for facilities using increasing number of interventions. The monitoring rate increased with greater use of interventions $(p=0.05$ for trend). When WBC rate was considered continuous the trend was more significant $(p=0.005), 3.8 \%$ increase for each additional intervention $(95 \% \mathrm{Cl} 1.2-6.4)$.

Table 1. Use and Effectiveness of Interventions to Improve WBC Monitoring Among 51 Participating Facilities

\begin{tabular}{|l|c|c|c|c|}
\hline \multirow{2}{*}{ Intervention } & \multirow{2}{*}{$\begin{array}{c}\text { Facility Use } \\
\text { N }\end{array}$} & \multicolumn{2}{|c|}{$\begin{array}{c}\text { Mean Rate of WBC Monitoring (\% of } \\
\text { patients) }\end{array}$} & \multirow{2}{*}{$\begin{array}{c}\text { Pot Using } \\
\text { Intervention }\end{array}$} \\
\cline { 3 - 5 } & $30(59 \%)$ & $57 \pm 16$ & $50 \pm 16$ & 0.13 \\
\hline $\begin{array}{l}\text { Electronic } \\
\text { Reminders }\end{array}$ & $27(53 \%)$ & $59 \pm 13$ & $47 \pm 18$ & 0.008 \\
\hline Provider Education & $26(52 \%)$ & $58 \pm 17$ & $50 \pm 14$ & 0.07 \\
\hline $\begin{array}{l}\text { Provider Request } \\
\text { for Management } \\
\text { Plan }\end{array}$ & $7(14 \%)$ & $57 \pm 14$ & $53 \pm 17$ & 0.33 \\
\hline Patient Calls & $6(12 \%)$ & $73 \pm 9$ & $52 \pm 15$ & 0.003 \\
\hline $\begin{array}{l}\text { Academic } \\
\text { Detailing }\end{array}$ & $5(10 \%)$ & $66 \pm 11$ & $53 \pm 16$ & 0.09 \\
\hline $\begin{array}{l}\text { Draft Orders for } \\
\text { WBC }\end{array}$ & $2(4 \%)$ & $44 \pm 9$ & $53 \pm 17$ & 0.47 \\
\hline Patient Mailing & & & & \\
\hline
\end{tabular}


Table 2. Reasons for Lack of Participation

\begin{tabular}{|l|c|}
\hline & $\mathbf{N}(\%)^{\star}$ \\
\hline Facilities Previously Participating (N=14) & \\
\hline Not enough patients to make it worthwhile & $9 / 14(64 \%)$ \\
\hline Providers Adequately Educated & $5 / 14(36 \%)$ \\
\hline Not a high priority safety issue & $1 / 14(7 \%)$ \\
\hline Any Reason Provided & $12 / 14(86 \%)$ \\
\hline Facilities that Never Participated (N=27) & \\
\hline Too time consuming & $8 / 27(30 \%)$ \\
\hline Not enough patients to make it worthwhile & $6 / 27(22 \%)$ \\
\hline Not real time data & $4 / 27(15 \%)$ \\
\hline Need help from other services to implement & $2 / 27(7 \%)$ \\
\hline Not a high priority safety issue & $2 / 27(7 \%)$ \\
\hline Not Appropriate work for a pharmacist & $1 / 27(4 \%)$ \\
\hline Information Technology (IT) limitation & $1 / 27(4 \%)$ \\
\hline Any Reason Provided & $19 / 27(70 \%)$ \\
\hline
\end{tabular}

${ }^{*}$ More than one reason could be provided for each category. 
Appendix.

\section{VA Medication Use Evaluation Tracker (MUET) Safety Initiative [3]}

Patients are identified if they are on active DMF treatment (defined as at least one filled prescription) during a fiscal quarter with at least one of two criteria 1) Absence of WBC count during the 90 days following a DMF prescription. 2) Most recent WBC $<2000 / \mathrm{mm} 3$ within 90 days of a DMF prescription.

Data are obtained from the VA Corporate Data Warehouse outpatient prescription data and are updated monthly. Laboratory data are updated daily. A list of at-risk patients are sent to each facility on a quarterly basis. Each facility is asked to provide a response for each patient (providing a reason for not intervening, or state that lab testing was ordered or that the medication dose was adjusted or discontinued). The pharmacy service at each facility can decide if and how they wish to intervene on any on any patient on the list. 


\section{Figures}

\section{Image not available with this version}

\section{Figure 1}

The rate of WBC monitoring is shown for facilities using increasing number of interventions. The monitoring rate increased with greater use of interventions ( $p=0.05$ for trend). When WBC rate was considered continuous the trend was more significant $(p=0.005), 3.8 \%$ increase for each additional intervention (95\% $\mathrm{Cl} 1.2-6.4)$.

\section{Supplementary Files}

This is a list of supplementary files associated with this preprint. Click to download.

- STROBEchecklistcohortMUET.pdf 